\title{
Новые данные о минералогии золото-уранового рудопроявления Ромпас, Финляндия
}

\author{
Полеховский Ю.С. ${ }^{1 *}$, Петров С.В. ${ }^{1}$, Калинин А.А. ${ }^{2}$, Коваль А.В. ${ }^{1}$ \\ ${ }^{1}$ Институт наук о Земле, СПбГУ, Санкт-Петербург, petrov64@gmail.com \\ ${ }^{2}$ Геологический институт КНЦ РАН, Anamumbl, kalinin@geoksc.apatity.ru
}

Аннотация. В аншлифах, изготовленных из образцов рудопроявления Ромпас установлено 10 видов рудных минералов: уранинит, самородное золото, мальдонит, монтбрейит, алтаит, мелонит, фробергит, теллурантимон, теллурид висмута ВіТе ${ }_{2}$, а также оксид теллура теллурит. Изучен состав минералов золота и теллуридов никеля, железа, свинца, висмута и сурьмы. Показано, что развитие минерализации золота и теллуридов проходило многостадийно, и золото неоднократно переотлагалось, сформировав несколько генераций. Такие минералы, как монтбрейит, мелонит, фробергит, теллурантимон, теллурид висмута ВіТе ${ }_{2}$ и теллурит установлены на рудопроявлении Ромпас впервые.

Ключевые слова: Ромпас, золото-урановая минерализация, золото, мальдонит, монтбрейит, теллуриды, теллурит.

\section{New Data on Mineralogy of the Rompas Uranium-Gold prospect, Finland}

\author{
Polekhovsky Yu.S. ${ }^{1}$, Petrov S.V. ${ }^{1}$, Kalinin A.A. ${ }^{2}$, Koval A.V. ${ }^{1}$ \\ ${ }^{I}$ Institute of Earth Sciences, S-Peterburg State University, S-Peterburg, petrov64@gmail.com \\ ${ }^{2}$ Geological institute KSC RAS, Apatity, kalinin@geoksc.apatity.ru
}

\begin{abstract}
Ten ore minerals have been found in the specimen from the Rompas prospect: uraninite, native gold, maldonite, montbrayite, altaite, melonite, frobergite, tellurantimony, bismuth telluride BiTe ${ }_{2}$, tellurium oxide tellurite. Chemical composition of minerals of gold and of tellurides has been studied. Deposition of gold and tellurides has a multi-stage character, gold was redeposited and formed few generations. Montbrayite, melonite, froberfite, tellurantimony, bismuth telluride $\mathrm{BiTe}_{2}$, tellurite have not been reported earlier in the Rompas prospect.

Key words: Rompas, uranium-gold mineralization, gold, maldonite, montbrayite, tellurides, tellurite.
\end{abstract}

Рудопроявление Ромпас расположено в северной части раннепротерозойского сланцевого пояса Перапохья. Участок рудопроявления сложен метабазальтами с небольшим количеством вулканокластитов, карбонатными породами, кварцитами и графитсодержащими биотитовыми глиноземистыми сланцами (Mineral deposits..., 2015, Molnár et al., 2016, 2017, Гребенкин и др., 2015, Калинин, 2018). Породы претерпели метаморфизм амфиболитовой фации в палеопротерозойское время.

Как метавулканиты, так и метаосадочные породы содержат амфибол-карбонат-кварцевые жилы мощностью до 30 см (Molnár et al., 2016, Гребенкин и др., 2015). Жилы смяты в складки вместе с вмещающими их породами, то есть формировались до пика регионального метаморфизма. Более поздние деформации отразились в будинировании жил, сопровождавшимся переотложением жильных минералов и образованием сигарообразных метровой длины обособлений доломита. С жилами и обособлениями доломита связаны аномально высокие концентрации урана и золота, повышенное содержание битуминозного вещества, развитие порфиробластического уранинита.

Золото-урановая минерализация образуется исключительно в жилах, приуроченных к метабазальтам, а точно такие же по составу и текстурно-структурным особенностям жилы в метаосадках безрудные (Mineral deposits..., 2015, Molnár et al., 2016). Минерализация урана и золота отмечается

\footnotetext{
$1^{*}$ Данная работа стала одной из последних для Юрия Степановича Полеховского. Юрий Степанович всегда проявлял интерес к новым объектам, новым минералам, вот и этот небольшой образец, подаренный Н.Б. Филипповым, был им изучен весьма основательно. Именно основательность, порядок, внимание к мелочам всегда отличали этого замечательного ученого и известного педагога. Мы взяли на себя труд обработать результаты исследований Ю.С. Полеховского и представить их в виде этой небольшой публикации.
} 

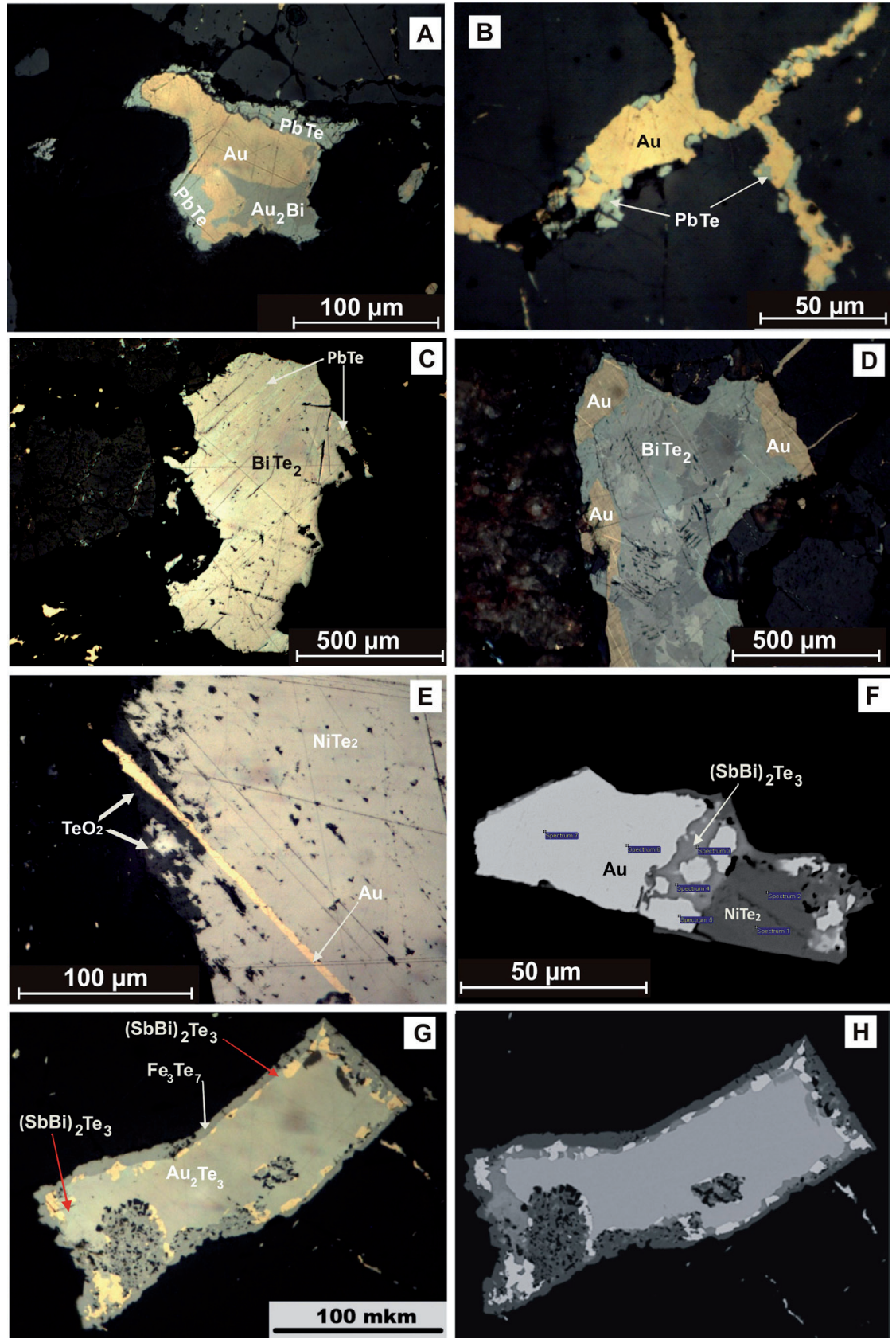

Рис. 1. Золото в срастании с теллуридами, рудопроявление Ромпас.

A - висмутид $\mathrm{Au}$ (мальдонит) в ассоциации с самородным золотом, отраженный свет, без анализатора. В - самородное золото с алтаитом в прожилках в уранините, отраженный свет, без анализатора. С - теллурид Вi замещается алтаитом по спайности и с краев, отраженный свет, без анализатора. D - анизотропный теллурид Bi с золотом, отраженный свет, с анализатором. Е - мелонит с выделением самородного золота по спайности, мелонит по краю замещается диоксидом теллура; отраженный свет, без анализатора. F - BSE-фото теллуридов сурьмы и висмута, развивающихся между золотом и мелонитом $\left(\mathrm{NiTe}_{2}\right)$. G-H - монтбрейит с теллурантимоном и самородным золотом обрастает каймой фробергита: $\mathrm{G}$ - отраженный свет, без анализатора. H - BSE-photo.

Fig. 1. Gold with tellurides, Rompas prospect.

A - maldonite with native gold and altaite, reflected light, one polarizer. B - native gold with altaite in veinlets in uraninite, reflected light, no polarizer. $\mathrm{C}$ - bismuth telluride, replaced by altaite along cleavage and at the grain boundaries, reflected light, no polarizer. D - bismuth telluride with gold, reflected light, with a polarizer. E - native gold along cleavage in melonite, reflected light, one polarizer. F - tellurantimony with gold and melonite, BSE-photo. G-H - overgrow of frobergite on the grain of montbrayite with tellurantimony and native gold: $\mathrm{G}$ - reflected light, no polarizer; $\mathrm{H}$ - BSE-photo. 
как в пределах самих амфибол-карбонат-кварцевых жил, так и в их экзоконтактовых зонах в скарноидах (Гребенкин и др., 2015).

Самородное золото и его интерметаллические соединения на рудопроявлении всегда связаны с уранинитом (рис. 1) или с уранинитом и керогенами (Molnár et al., 2016).

Золото выполняет трещины в уранините, образует тонкую вкрапленность в карбонатах вблизи зерен уранинита, отмечается по трещинам усыхания в выделениях углеродистого вещества или нарастает на поверхность зерен керогенов (Molnár et al., 2016). Кроме золота в составе минерализации были отмечены галенит, алтаит, никелин, хунчунит, Рb-содержащий мальдонит, молибденит, кобальтин, пирротин, пентландит, пирит, халькопирит (Molnár et al., 2016).

Самородное золото наблюдалось нами в виде отдельных мономинеральных выделений размером до 7 мм (рис. 1, А), в прожилках по трещинам в уранините (рис. 1, В), а также реакционных каймах между теллуридами в виде цепочек мелких зерен (рис. 1, G).

Золото весьма высокопробное: средний состав изученных нами зерен (n=31): Au - 96.95 \% до $99.25 \%$, в среднем 98.39 мас. \%, Ag от 0 до $1.90 \%$, в среднем $0.87 \%$, Cu от 0.39 до 1.57, среднее 0.72 \%; кроме того, есть два аномальных по содержанию серебра выделения золота с 3.42 и $3.70 \% \mathrm{Ag}$.

Мальдонит $\mathrm{Au}_{2} \mathrm{Bi}$ установлен в ассоциации с самородным золотом, зерно золота и мальдонита по краям замещается алтаитом (рис. 1, А). В составе минерала выявляется избыток катиона (табл. 1). Ранее на рудопроявлении Ромпас был описан минерал, близкий по составу к мальдониту (Molnár et al., 2016), но с высоким содержанием свинца, которое превышает содержание висмута: $\mathrm{Au}_{2.07-2.12}\left(\mathrm{~Pb}_{0.51-0.58} \mathrm{Bi}_{0.42-0.49}\right)$. По этой причине такое соединение правильнее было бы назвать висмутсодержащим хунчунитом. Впрочем, не исключено, что речь идет о новом минеральном виде с формулой $\mathrm{Au}_{4} \mathrm{PbBi}$.

Монтбрейит $\mathrm{Au}_{2} \mathrm{Te}_{3}$ отмечен в виде гипидиоморфного зерна размером 150×50 мкм в центре полиминерального зонального образования (рис. $1 \mathrm{G}, \mathrm{H}$ ). По монтбрейиту узкой полосой развивается теллурид сурьмы и висмута, к которому приурочена цепочка мелких (до 10 мкм) выделений самородного золота, и все это обрастает каймой фробергита (рис. $2 \mathrm{G}, \mathrm{H}$ ). В химическом составе монтбрейита (табл. 1) обнаруживается примесь висмута, но формульные коэффициенты близки к теоретическим. В составе фробергита отмечается некоторый дефицит железа (табл. 1).

Теллурид сурьмы и висмута (теллурантимон - ?) выявлен в виде каймы по границе монтбрейита $\left(\mathrm{Au}_{2} \mathrm{Te}_{3}\right)$ и теллурида железа (рис. $1 \mathrm{G}, \mathrm{H}$ ), а также отмечен по границе между золотом и мелонитом (рис.1, F). Цвет минерала белый с голубоватым оттенком, он отчетливо анизотропный и по оптическим свойствам отвечает теллурантимону $\mathrm{Sb}_{2} \mathrm{Te}_{3}$. В составе минерала установлена значимая примесь висмута (табл. 1), но формула минерала хорошо рассчитываются на (Sb,Bi) ${ }_{2.00} \mathrm{Te}_{3.00}$. Boзможно, выявленная минеральная фаза является промежуточной разновидностью между теллурантимоном и теллуровисмутитом.

Теллурид висмута ВіТе 2 образует отдельные зерна, кроме того, отмечен в ассоциации с самородным золотом (рис. C, D). Минерал белый с розоватым оттенком и слабым двуотражением, анизотропия отчетливая (рис. 1, D). По трещинам спайности в зерне ВіТе 2 развивается алтаит. По химическому составу (табл. 1) минерал соответствует формуле ВіТе ${ }_{2}$, но теллуриды висмута с таким соотношением элементов пока неизвестны. Требуется доизучение минерала с получением дополнительных данных.

Алтаит наблюдается в ассоциации с золотом в прожилках в уранините, развивается в виде каймы по золоту и мальдониту, замещает теллурид висмута по трещинам спайности (рис. 1, А-С). В составе алтаита иногда обнаруживается примесь висмута (табл. 1), но формульные коэффициенты близки к стехиометрическим.

Мелонит отмечен в срастании с золотом, иногда золото развито по спайности в мелоните (рис. 1 Е). Замещается мелонит диоксидом теллура. Химические составы мелонита и теллурита (табл. 1,2$)$ близки к теоретическим. 
Таблица 1. Состав минералов золота и теллуридов рудопроявления Ромпас, масс. \%.

Table 1. Composition of gold minerals and tellurides from the Rompas prospect, wt. \%.

\begin{tabular}{|c|c|c|c|c|c|c|c|c|c|}
\hline Минерал & $\mathrm{Fe}$ & $\mathrm{Ni}$ & $\mathrm{Au}$ & $\mathrm{Pb}$ & $\mathrm{Sb}$ & $\mathrm{Bi}$ & $\mathrm{Te}$ & Сумма & $\begin{array}{c}\text { Кристаллохимическая } \\
\text { формула }\end{array}$ \\
\hline \multirow{4}{*}{ Мальдонит } & - & - & 68.25 & - & - & 31.75 & - & 100.00 & $\mathrm{Au}_{2.28} \mathrm{Bi}_{1.00}$ \\
\hline & - & - & 67.40 & - & - & 32.60 & - & 100.00 & $\mathrm{Au}_{2.19} \mathrm{Bi}_{1.00}$ \\
\hline & - & - & 68.04 & - & - & 31.96 & - & 100.00 & $\mathrm{Au}_{2.26} \mathrm{Bi}_{1.00}$ \\
\hline & - & - & 67.58 & - & - & 32.42 & - & 100.00 & $\mathrm{Au}_{2.21} \mathrm{Bi}_{1.00}$ \\
\hline \multirow{3}{*}{ Монтбрейит } & - & - & 50.00 & - & - & 2.15 & 47.85 & 100.00 & $\mathrm{Au}_{1.98\left(\mathrm{Te}_{2.92} \mathrm{Bi}_{0.08) 3.00}\right.}$ \\
\hline & - & - & 49.47 & - & - & 2.72 & 47.81 & 100.00 & $\mathrm{Au}_{1.94(} \mathrm{Te}_{2.90} \mathrm{Bi}_{0.10) 3.00}$ \\
\hline & - & - & 49.30 & - & - & 2.99 & 47.72 & 100.00 & $\mathrm{Au}_{1.93(} \mathrm{Te}_{2.89} \mathrm{Bi}_{0.11) 3.00}$ \\
\hline \multirow{3}{*}{$\begin{array}{l}\text { Теллурид } \\
\text { висмута }\end{array}$} & - & - & - & - & - & 43.73 & 56.27 & 100.00 & $\mathrm{Bi}_{0.95} \mathrm{Te}_{2.00}$ \\
\hline & - & - & - & - & - & 43.76 & 56.24 & 100.00 & $\mathrm{Bi}_{0.95} \mathrm{Te}_{2.00}$ \\
\hline & - & - & - & - & - & 43.71 & 56.29 & 100.00 & $\mathrm{Bi}_{0.95} \mathrm{Te}_{2.00}$ \\
\hline \multirow{10}{*}{ Мелонит } & - & 18.80 & - & - & - & - & 81.20 & 100.00 & $\mathrm{Ni}_{1.01} \mathrm{Te}_{2.00}$ \\
\hline & - & 18.82 & - & - & - & - & 81.18 & 100.00 & $\mathrm{Ni}_{1.01} \mathrm{Te}_{2.00}$ \\
\hline & - & 19.74 & - & - & - & - & 80.26 & 100.00 & $\mathrm{Ni}_{1.07} \mathrm{Te}_{2.00}$ \\
\hline & - & 19.87 & - & - & - & - & 80.13 & 100.00 & $\mathrm{Ni}_{1.08} \mathrm{Te}_{2.00}$ \\
\hline & - & 17.56 & - & - & - & - & 82.44 & 100.00 & $\mathrm{Ni}_{0.93} \mathrm{Te}_{2.00}$ \\
\hline & - & 17.07 & - & - & - & - & 82.93 & 100.00 & $\mathrm{Ni}_{0.89} \mathrm{Te}_{2.00}$ \\
\hline & - & 18.60 & - & - & - & - & 81.40 & 100.00 & $\mathrm{Ni}_{0.99} \mathrm{Te}_{2.00}$ \\
\hline & - & 18.62 & - & - & - & - & 81.38 & 100.00 & $\mathrm{Ni}_{0.99} \mathrm{Te}_{2.00}$ \\
\hline & - & 17.80 & - & - & - & - & 82.20 & 100.00 & $\mathrm{Ni}_{0.94} \mathrm{Te}_{2.00}$ \\
\hline & - & 16.95 & - & - & - & - & 83.05 & 100.00 & $\mathrm{Ni}_{0.85} \mathrm{Te}_{2.00}$ \\
\hline \multirow{4}{*}{ Фробергит } & 15.76 & - & - & - & - & - & 84.24 & 100.00 & $\mathrm{Fe}_{0.86} \mathrm{Te}_{2.00}$ \\
\hline & 15.78 & - & - & - & - & - & 84.22 & 100.00 & $\mathrm{Fe}_{0.86} \mathrm{Te}_{2.00}$ \\
\hline & 15.85 & - & - & - & - & - & 84.15 & 100.00 & $\mathrm{Fe}_{0.86} \mathrm{Te}_{2.00}$ \\
\hline & 15.98 & - & - & - & - & - & 84.02 & 100.00 & $\mathrm{Fe}_{0.87} \mathrm{Te}_{2.00}$ \\
\hline \multirow{8}{*}{$\begin{array}{l}\text { Теллурид } \\
\text { сурьмы } \\
\text { и висмута }\end{array}$} & - & - & - & - & 19.01 & 25.23 & 55.76 & 100.00 & ${ }_{1} \mathrm{Sb}_{1.07} \mathrm{Bi}_{0.8311 .90} \mathrm{Te}_{3.00}$ \\
\hline & - & - & - & - & 19.38 & 24.90 & 55.72 & 100.00 & ${ }_{1} \mathrm{Sb}_{1.09} \mathrm{Bi}_{0.82) 1.91} \mathrm{Te}_{3.00}$ \\
\hline & - & - & - & - & 25.80 & 16.02 & 58.18 & 100.00 & ${ }_{(} \mathrm{Sb}_{1.39} \mathrm{Bi}_{0.501 .89} \mathrm{Te}_{3.00}$ \\
\hline & - & - & - & - & 26.22 & 16.07 & 57.71 & 100.00 & ${ }_{(} \mathrm{Sb}_{1.43} \mathrm{Bi}_{0.511) .94} \mathrm{Te}_{3.00}$ \\
\hline & - & - & - & - & 27.27 & 14.79 & 57.95 & 100.00 & $\mathrm{Sb}_{1.48} \mathrm{Bi}_{0.47) 1.95} \mathrm{Te}_{3.00}$ \\
\hline & - & - & - & - & 27.07 & 14.19 & 58.74 & 100.00 & ${ }_{(} \mathrm{Sb}_{1.45} \mathrm{Bi}_{0.44) .89} \mathrm{Te}_{3.00}$ \\
\hline & - & - & - & - & 26.33 & 15.92 & 57.75 & 100.00 & ${ }_{(} \mathrm{Sb}_{1.43} \mathrm{Bi}_{0.50) 1.93} \mathrm{Te}_{3.00}$ \\
\hline & - & - & - & - & 27.52 & 13.80 & 58.67 & 100.00 & ${ }_{1} \mathrm{Sb}_{1.47} \mathrm{Bi}_{0.43) 1.90} \mathrm{Te}_{3.00}$ \\
\hline \multirow{9}{*}{ Алтаит } & - & - & - & 64.20 & - & н.обн. & 35.80 & 100.00 & $\mathrm{~Pb}_{1.10} \mathrm{Te}_{1.00}$ \\
\hline & - & - & - & 62.62 & - & н.обн. & 37.38 & 100.00 & $\mathrm{~Pb}_{1.03} \mathrm{Te}_{1.00}$ \\
\hline & - & - & - & 62.00 & - & н.обн. & 38.00 & 100.00 & $\mathrm{~Pb}_{1.10} \mathrm{Te}_{1.00}$ \\
\hline & - & - & - & 62.77 & - & н.обн. & 37.23 & 100.00 & $\mathrm{~Pb}_{1.04} \mathrm{Te}_{1.00}$ \\
\hline & - & - & - & 62.32 & - & н.обн. & 37.68 & 100.00 & $\mathrm{~Pb}_{1.02} \mathrm{Te}_{1.00}$ \\
\hline & - & - & - & 60.41 & - & 2.59 & 37.00 & 100.00 & $\left(\mathrm{~Pb}_{1.01} \mathrm{Bi}_{0.04}\right)_{1.05} \mathrm{Te}_{1.00}$ \\
\hline & - & - & - & 61.90 & - & н.обн. & 38.10 & 100.00 & $\mathrm{~Pb}_{1.00} \mathrm{Te}_{1.00}$ \\
\hline & - & - & - & 59.67 & - & 4.13 & 36.20 & 100.00 & $\left(\mathrm{~Pb}_{1.02} \mathrm{Bi}_{0.07}\right)_{1.09} \mathrm{Te}_{1.00}$ \\
\hline & - & - & - & 57.36 & - & 6.63 & 36.01 & 100.00 & $\left(\mathrm{~Pb}_{0.98} \mathrm{Bi}_{0.11}\right)_{1.09} \mathrm{Te}_{1.00}$ \\
\hline
\end{tabular}

Примечания: н.обн. - элемент не обнаружен; прочерк - элемент не определялся. 
Таблица 2. Химический состав диоксида теллура, масс. \%.

Table 2. Composition of tellurium dioxide, wt. \%.

\begin{tabular}{|c|c|c|c|}
\hline $\mathrm{O}$ & Те & Сумма & $\begin{array}{c}\text { Кристаллохимическая } \\
\text { формула }\end{array}$ \\
\hline 19.06 & 81.1 & 100.16 & $\mathrm{Te}_{1.07} \mathrm{O}_{2.00}$ \\
\hline 20.07 & 80.81 & 100.88 & $\mathrm{Te}_{1.01} \mathrm{O}_{2.00}$ \\
\hline
\end{tabular}

Наблюдаемые взаимоотношения минералов золота, теллура, висмута (например, рис. 1 А, В, F, G) говорят о многостадийной истории рудогенеза. Понятно, что развитие рассматриваемой минерализации проходило после отложения крупнозернистого уранинита. К ранним теллуридам следует отнести монтбрейит, никелин, теллурид висмута, позднее отлагался теллурид сурьмы и висмута, последними - алтаит и фробергит. Что касается золота, то, вполне вероятно, оно неоднократно переотлагалось, сформировав несколько генераций.

\section{Литература}

1. Гребенкин Н.А., Леденева Н.В., Филиппов Н.Б., Житников В.А., Литвиненко В.И. Особенности уранзолоторудных проявлений группы Ромпас и объекта Палокас (Северная Финляндия) // Разведка и охрана недр. 2015. № 5. С. 11-15.

2. Калинин А.А. Золото в метаморфических комплексах северо-восточной части Фенноскандинавского щита. Апатиты. ФИЦ КНЦ РАН. 2018. 250 c.

3. Mineral deposits of Finland / Maier W.D., Lahtinen R., O'Brien H. (editors). Amsterdam: Elsevier, 2015. 792 p.

4. Molnár, F.; Oduro, H.; Cook, N.D.J.; Pohjolainen, E.; Takács, Á.; O’Brien, H.; Pakkanen, L.; Johanson, B.; Wirth, R. Association of gold with uraninite and pyrobitumen in the metavolcanic rock hosted hydrothermal Au-U mineralisation at Rompas, Peräpohja Schist Belt, northern Finland // Mineral. Depos. 2016. V. 51. P. 681-702.

5. Molnár, F.; O’Brien, H.; Stein, H., Cook, N.D.J.; Geochronology of Hydrothermal Processes Leading to the Formation of the Au-U Mineralization at the Rompas Prospect, Peräpohja Belt, Northern Finland: Application of Paired U-Pb Dating of Uraninite and Re-Os Dating of Molybdenite to the Identification of Multiple Hydrothermal Events in a Metamorphic Terrane //Minerals. 2017. V. 7(9). 171 p. 